\title{
The Impact of an eLearning Course on Nurses' Attitudes towards Mental Illness
}

\author{
Anneli Pitkänen1, Raija Kontio ${ }^{2,3}$, Mari Lahti4,5, Jouko Katajisto6, Maritta Välimäki ${ }^{5,7}$ \\ ${ }^{1}$ Tampere University Hospital, Tampere, Finland \\ ${ }^{2}$ Helsinki University, Helsinki, Finland \\ ${ }^{3}$ Department of Psychiatry, Helsinki University Hospital, Helsinki, Finland \\ ${ }^{4}$ Turku University of Applied Science, Turku, Finland \\ ${ }^{5}$ Department of Nursing Science, University of Turku, Turku, Finland \\ ${ }^{6}$ Department of Statistics, University of Turku, Turku, Finland \\ ${ }^{7}$ Turku University Hospital, Turku, Finland \\ Email: anneli.pitkanen@pshp.fi
}

Received 27 September 2015; accepted 20 November 2015; published 23 November 2015

Copyright (C) 2015 by authors and Scientific Research Publishing Inc.

This work is licensed under the Creative Commons Attribution International License (CC BY).

http://creativecommons.org/licenses/by/4.0/

(c) (i) Open Access

\begin{abstract}
Patients with mental illness are stigmatized. Health care professionals may even perpetuate stigma towards mental illness. Thus it is important to ensure that health care professionals have positive attitudes towards patients with mental illness. The aim of this study was to estimate the impact of an eLearning course on psychiatric nurses' attitudes towards mental illness. A cluster-randomized trial (ISRCTN32869544) design was used. Twelve wards were randomly assigned to the eLearning course (ePsychNurse.Net) group or the education as a usual group. The participants $(N=228)$ were allocated to the intervention $(n=115)$ or control group $(n=113)$ according their baseline ward affiliation. Attitudes were rated according to the Community Attitude towards the Mentally Ill scale. Both groups were found to have positive, not stigmatized attitudes towards mental illness. No statistically significant changes were found at three-month or nine-month follow-up. It may be that by developing the ePsychNurse.Net course to include more material related to nurses' attitudes and as nurses become more familiar with eLearning, the course may be effective in shaping nurses' attitudes towards mental illness. On the other hand, our study's ninemonth time span may have been too short to change nurses' attitudes.
\end{abstract}

\section{Keywords}

eLearning, Psychiatric Nursing, Cluster-Randomized Intervention Trial, Stigma 


\section{Introduction}

In recent years, mental health has been recognized as a priority area in most European countries [1]. One key challenge on the political agenda is tackling stigma [2] [3]. Stigma of mental illness is a global problem which may lead to negative discrimination [4] [5] affects in many areas of life [1], such as health care services, housing, education, employment and social relationships [6]. It may also lead to poor quality of life for these people [5]. Moreover, stigma and discrimination against people with mental illness is the main obstacle to the development of mental health care [7]. It is important to ensure that mental health professionals have positive, not stigmatized attitudes towards patients with mental illness [8]. Nurses' positive attitudes may be defined as holding sympathetic and compassionate views towards people with mental illness and disagreeing with the view that those people are inferior or a threat to society and thus need to be excluded or coercively handed [9].

Nurses' positive attitudes are crucial since stigmatized attitudes can have serious implications for patients' recovery [8]. Earlier studies have shown that mental health nurses' attitudes towards mental illness differ across countries [9]. In general, nurses who work in mental health settings have largely positive attitudes towards mental illness [9] and more positive attitudes than general medical nurses [10]. However, stigmatized attitudes are not unknown among mental health professionals [8]. Some research findings indicate that nurses have more stigmatized attitudes towards mental illness than do psychiatrists or the general population [4]. Moreover they may even contribute to perpetuating stigma regarding mental illness [10].

Stigma may not only be seen in nurses' negative attitudes but can contribute to the abuse of human rights in institutions [3]. It is noteworthy that nurses' positive attitudes may reduce coercive interventions [11] since negative experience of discrimination may be related to prior coercive mental health service intervention [5]. Thus it is important to ensure that nurses have positive attitudes towards patients with mental illness. Vocational education may have a positive effect on nurses' attitudes and values in clinical work [12] [13].

This study is based on a large project conducted in six European countries and funded by the European Commission of Leonardo da Vinci (FI-06-B-F-PP-160701). The overall goal of the collaborative project was to ensure high quality, ethically appropriate and therapeutically effective interventions to enable nurses to manage distressed and disturbed patients on psychiatric wards. Based on this goal, an eLearning course (ePsychNurse.Net) was developed [14] since e-learning has been dramatically increased as a promising new method of delivering courses [15].

We have earlier reported findings from Finnish data related to how the ePsychNurse.Net course impacts on knowledge, attitudes towards seclusion and restraint, job satisfaction and general self-efficacy [16] [17], how nurses are able to transfer knowledge from e-learning course to their clinical practice [18] and how the course impacts on the rates and duration of seclusion and mechanical restraint [19]. The aim of this study was to explore the impact of the ePsychNurse.Net course on nurses' attitudes towards mental illness. The hypothesis was that nurses completing the ePsychNurse.Net course would have more positive attitudes towards mental illness.

\section{Materials and Methods}

\subsection{Design}

A multicentre randomized controlled open label design was used and the study protocol has been registered (ISRCTN32869544). The study was conducted according to CONSORT guidelines [20].

\subsection{Study Setting, Recruitment and Participants}

The study was conducted from January to November 2009 on twelve closed acute psychiatric wards in three hospitals in Southern Finland. There were 20 wards that met inclusion criteria: close acute inpatient ward, using restraint and seclusion, not involved same kind of research or developing project. Twelve wards applied to participate and were enrolled. Eligible participants were registered nurses working on the study wards for over three months, aged over 18 years, having a sufficient command of Finnish language, and being willing to participate. Participants' attitudes to mental illness were assessed two weeks before the intervention (baseline), as well as 3-month and 9-month follow-ups. Figure 1 describes the flow of participants.

\subsection{Interventions}

The intervention was a three-month eLearning course (“ePsychNurse.Net”) developed by collaborative work 


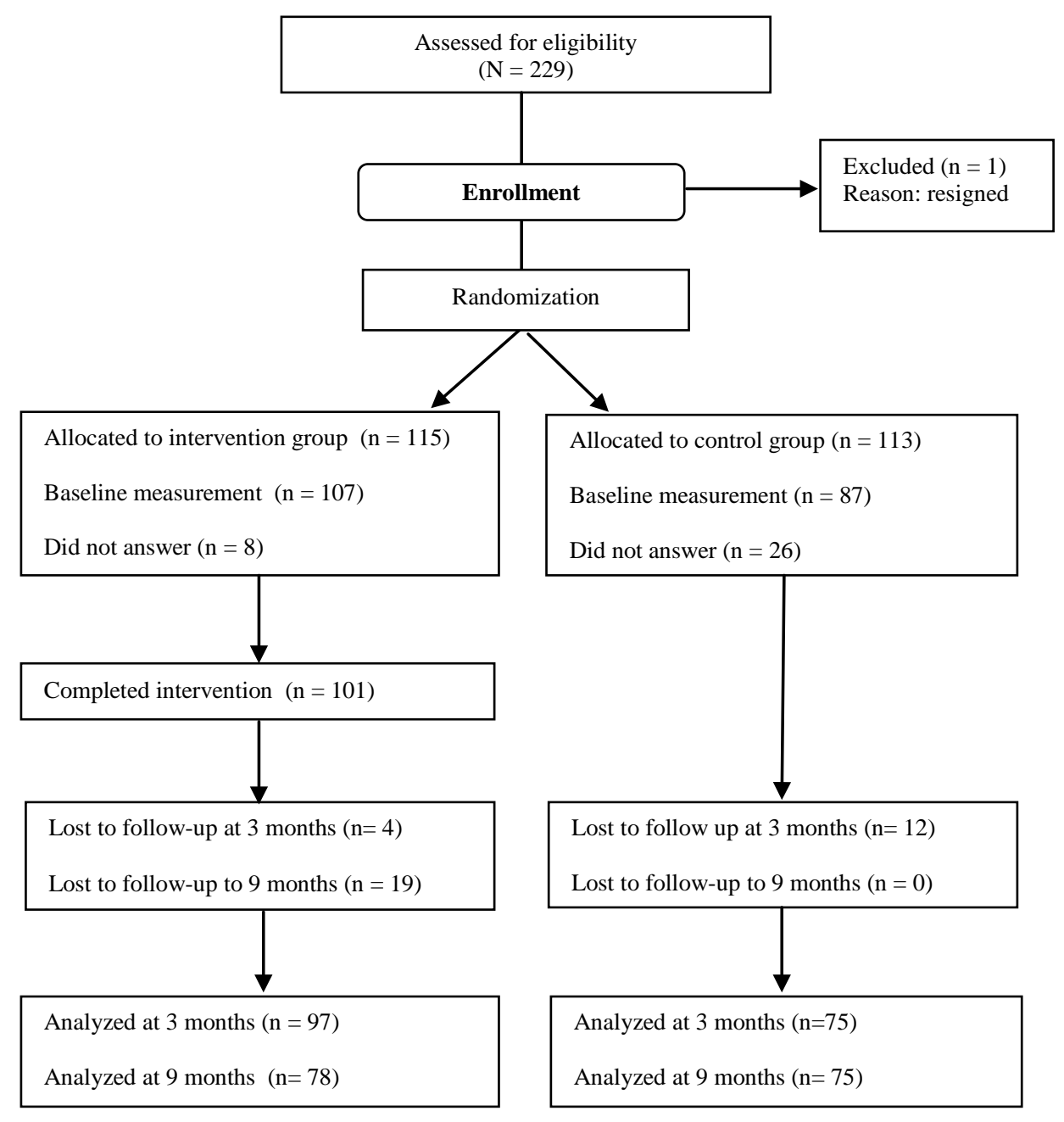

Figure 1. The participant flow diagram.

among experts in Finland, the UK, Ireland, Italy, Lithuania and Portugal in the ePsychNurse.Net project (20062008). Although the main aim of the course is to teach nurses to manage distressed and disturbed patients in psychiatric wards, the content of the course includes many elements related psychiatric nurses' attitudes towards mental illness since nurses' positive attitudes are important for treating these patients. The ePsychNurse.Net course cover specific learning methods and includes six modules: 1) legal and ethical issues; 2) behaviour-related factors; 3) therapeutic relationship; 4) self-awareness; 5) teamwork and 6) integrating knowledge with practice. The whole course took $120 \mathrm{~h}$ ( $40 \mathrm{~h}$ in working hours and the rest in own time) over three months. It was taken on module-by-module bases in pre-defined order. The main pedagogical approach involved reflective learning [21] because reflection can lead to positive outcomes in students' clinical practice and change their perceptions [22]; for example the self-awareness techniques to gain a more profound understanding of their personal habits and ways of behaving. Several learning methods were used: reading material, Power Point lectures, virtual patients' cases, discussion, online chat option with tutors, reflective writing and assignments. During the course the nurses were supervised by twelve trained tutors. The control group had continuing vocational education as usual. It included different topics of psychiatric care and was irregular and fragmental.

\subsection{Outcome Measures}

The Community Attitude towards the Mentally Ill (CAMI; [23] [24]) scale was used in this study. The instrument includes 40 items with four subscales: 1) Authoritarianism; 2) Benevolence; 3) Social restrictiveness and 4) Community mental health ideology. Authoritarianism refers to a view of mentally ill persons as someone infe- 
rior requiring coercive handling. Benevolence reflects a sympathetic view of those suffering from a mental illness. Social restrictiveness refers to the belief that the mentally ill patients are a threat to society. Community mental health ideology reflects acceptance of mental health services and mental ill patients in the community. Five-point Likert type responses are provided for each item ranging from "strongly agree" (1) to "strongly disagree" (5). Each subscale consists of 10 items, and five of these are reverse-coded. A mean score is calculated for each subscale. Higher scores on the authoritarianism subscale and on the Social Restrictiveness subscale reflect negative attitudes while higher scores on the Benevolence subscale and on the Community Mental Health Ideology subscale suggest a more positive view. The reliability of CAMI ranges from alpha 0.68 to 0.88 for different subscales and the scales correlate highly with each other [24]. Three items were modified to ensure that the language was gender neutral, but still ensuring that the original meaning was retained. CAMI was translated into Finnish according to standard procedures for the purposes of this study [25]. Although CAMI was developed to measure the general population's attitude towards community mental health facilities [23], it has been used during the past 30 years among a wide variety of participants and in a number of differing contexts [26]-[28] also among nurses in psychiatric settings [9] [29].

The background information included the nurses' gender, age, length of working experience in psychiatry, work position, continuing education received on mental health and coercion, and experiences of violence at work.

\subsection{Randomization}

The study wards were randomized by a coin to allocate them either to the ePsychNurse.Net group or to the training-as-usual group. After wards' randomization the participants $(\mathrm{N}=228)$ were allocated to the intervention $(n=115)$ or control group $(n=113)$ according to their baseline ward affiliation. This study was conducted in a real-life clinical setting, therefore we could conceal allocation only until the start of the intervention. Participants and researchers could not be blinded.

\subsection{Ethical Considerations}

The study was evaluated by the local Ethics Committee (HUS 13.3.2007, §50) and authorized by the directors of the study organizations. It was emphasized that although every nurse in the study wards expected to participate the ePsychNurse.Net course, participation in the study was voluntary and refusal would not affect the working conditions. Data were treated in confidence [30].

\subsection{Data Analysis}

Sum variables according to theoretical categories were formed. These were obtained by adding up the coded answers and dividing the calculated sum by the number of variables so that the sum variables had the same scale as the individual items. Consequently, the range of the sum variables' was the same as in the original question. The four sum scales of CAMI were analysed and compared at different measuring points (baseline, 3-month and 9-month follow-up). Comparisons were conducted between the two groups for each measurement using two-sample t-test. Repeated measures analysis of variance and Bonferroni corrected contrasts were used to calculate significant changes between groups within time. A P-value of $<0.05$ was considered statistically significant. Analyses were performed with SPSS 16.0 software.

\section{Results}

\subsection{Baseline Data}

The CAMI was completed at baseline by 194 nurses (intervention group $n=107$, control group $n=87$ ). One hundred and six (55\%) were female, average age was 43 years (range: 24 - 64, SD: 9.2) and working experience in psychiatry varied from one month to 37 years (mean: 15.6 years, SD: 9.3). Most of the participants were registered nurses $(n=116 ; 60 \%)$ or mental health nurses $(n=62 ; 32 \%)$. Sixty-seven percent $(n=122)$ had received continuing education in psychiatric nursing and 58\% ( $\mathrm{n}=107)$ in coercion. Only one participant had no experiences of violence at work. There were no statistically significant differences in any characteristics, supporting the effectiveness of the random allocation. 


\subsection{Outcomes and Estimation}

No statistically significant findings were found between the study groups. Only in social restrictiveness at baseline there was a statistically significant difference $(p=0.040)$ between the study groups (Table 1$)$. Both groups were found to have positive attitudes towards mental illness. The control group had slightly more positive attitudes on all four sub-scales at all time-points.

Change in attitudes related to authoritarianism decreased slightly $(-0.01)$ in the intervention group and increased $(+0.03)$ in the control group during the nine months of follow-up. In benevolence both groups showed some decrease at nine months (intervention group -0.04, control group -0.02). Social restrictiveness increased in both groups (intervention group +0.03 , control group +0.04 ). In community mental health ideology there was a slight decrease $(-0.03)$ in the intervention group, while the control group rates were similar at baseline and at 9-month follow-up. In within-group analysis no statistically significant changes were found at three-month (p range from 0.577 to 1 ) or nine-month (p range from 0.361 to 0.952 ) follow-ups (Table 1 ).

\section{Discussion}

Our aim was to explore the impact of the ePsychNurse.Net course on nurses' attitudes related to mental illness. We found the nurses' attitudes in both study groups quite positive, but our hypothesis that nurses completing the ePsychNurse.Net course would have more positive attitudes towards mental illness than the control group was not upheld. In general, education has been shown to have some impact on nurses' attitudes [31] [32]. Our nurses' attitudes were already positive at baseline and this may be one reason why no statistically significant change occurred. Perhaps only a very potent training course would have the capacity to achieve a statistically significant change. On the other hand, reviews of the impacts of e-learning indicate that e-learning is not superior to traditional learning method when educating health care professionals [15] [33].

Change in attitudes is slow [34]. Thus, our study's nine-month time span may have been too short to internalize the new attitude. Moreover, the nurses in our study did not choose to attend the course because all nurses on the intervention wards were expected to take part in it which may have affected some nurses' motivation to study in the course and further to their learning outcomes. However, although the course was obligatory based on directors' decisions, the participation into the study was voluntary.

The lack of attitude change may also have been an expression of the inadequacy of the e-learning course. The e-learning course may be itself a rather new method. The use of eLearning may provoke ambivalence, negative perceptions [35] and some resistance [36]. This may be especially true in psychiatry, where information technologies are not yet as common as in other sectors [37]. Moreover, it has been argued that education alone is insufficient to change nurses' attitudes, especially in acute inpatient facilities [38] [39]. Thus it seems that ePsychNurse.Net alone is not enough to endure changes in staff attitudes but simultaneous use of other interventions is required.

Other research on this ePsychNurse.Net course found that the participating nurses would recommend it to other nurses. Moreover, they reported that knowledge gained during the course was transferrable to daily practice

Table 1. Impact of ePsychNurse.Net on nurses’ attitudes towards mental illness.

\begin{tabular}{|c|c|c|c|c|c|c|c|c|c|c|c|}
\hline & \multicolumn{3}{|c|}{ Baseline } & \multicolumn{4}{|c|}{3 months } & \multicolumn{4}{|c|}{9 months } \\
\hline & $\begin{array}{c}\text { Intervention } \\
\text { group } \\
(\mathrm{n}=107) \\
\text { mean (SD) }\end{array}$ & $\begin{array}{l}\text { Control } \\
\text { group } \\
(\mathrm{n}=87) \\
\text { mean (SD) }\end{array}$ & $\mathrm{p}$ & $\begin{array}{l}\text { Intervention } \\
\text { group } \\
(\mathrm{n}=97) \\
\text { mean (SD) }\end{array}$ & $\begin{array}{c}\text { Control } \\
\text { group } \\
(\mathrm{n}=75) \\
\text { mean (SD) }\end{array}$ & $\mathrm{p}$ & $\begin{array}{c}\text { Change } \\
\text { baseline to } \\
\text { 3-months } \\
\text { p }\end{array}$ & $\begin{array}{c}\text { Intervention } \\
\text { group } \\
(\mathrm{n}=78) \\
\text { mean (SD) }\end{array}$ & $\begin{array}{c}\text { Control } \\
\text { group } \\
(\mathrm{n}=75) \\
\text { mean (SD) }\end{array}$ & $\mathrm{p}$ & $\begin{array}{c}\text { Change } \\
\text { baseline to } \\
\text { 9-months } \\
\text { p }\end{array}$ \\
\hline Authoritarianism & $\begin{array}{l}2.19 \\
(0.42)\end{array}$ & $\begin{array}{c}2.08 \\
(0.39)\end{array}$ & 0.055 & $\begin{array}{c}2.20 \\
(0.42)\end{array}$ & $\begin{array}{c}2.08 \\
(0.39)\end{array}$ & 0.113 & 0.717 & $\begin{array}{c}2.18 \\
(0.46)\end{array}$ & $\begin{array}{c}2.11 \\
(0.43)\end{array}$ & 0.348 & 0.850 \\
\hline Benevolence & $\begin{array}{c}3.94 \\
(0.36)\end{array}$ & $\begin{array}{c}3.96 \\
(0.36)\end{array}$ & 0.595 & $\begin{array}{c}3.89 \\
(0.36)\end{array}$ & $\begin{array}{c}3.94 \\
(0.36)\end{array}$ & 0.370 & 0.577 & $\begin{array}{c}3.92 \\
(0.38)\end{array}$ & $\begin{array}{c}3.94 \\
(0.39)\end{array}$ & 0.716 & 0.361 \\
\hline $\begin{array}{c}\text { Social } \\
\text { restrictiveness }\end{array}$ & $\begin{array}{c}2.05 \\
(0.47)\end{array}$ & $\begin{array}{c}1.91 \\
(0.45)\end{array}$ & 0.040 & $\begin{array}{c}2.08 \\
(0.46)\end{array}$ & $\begin{array}{c}1.97 \\
(0.51)\end{array}$ & 0.131 & 0.887 & $\begin{array}{c}2.08 \\
(0.52)\end{array}$ & $\begin{array}{c}1.95 \\
(0.50)\end{array}$ & 0.113 & 0.753 \\
\hline $\begin{array}{c}\text { Community } \\
\text { mental } \\
\text { health ideology }\end{array}$ & $\begin{array}{c}3.69 \\
(0.59)\end{array}$ & $\begin{array}{c}3.77 \\
(0.53)\end{array}$ & 0.318 & $\begin{array}{c}3.66 \\
(0.61)\end{array}$ & $\begin{array}{c}3.78 \\
(0.60)\end{array}$ & 0.194 & 1.000 & $\begin{array}{c}3.66 \\
(0.66)\end{array}$ & $\begin{array}{c}3.77 \\
(0.61)\end{array}$ & 0.277 & 0.952 \\
\hline
\end{tabular}


and that the course gave them useful ideas for developing their daily work [18]. In future, in light of our results if the object is to improve the nurses attitudes towards mental illness, these different aspects should be focused on more comprehensively in the course. This is important since stigmatization of mental illness is a global problem [5], including psychiatric health care settings [10]. It is also important to note that professionals may be the perpetuators of stigma towards mental illness [10]. Educational interventions are important since although direct impacts on attitudes are not achieved an indirect impact might occur through increased skills to treat psychiatric patients [40]. The ePsychNurse.Net course offers a new educational intervention to be implemented internationally since the course was developed by collaborative work among experts from six European countries.

In interpreting the current results, there are some additional areas of consideration, including how attitudes were assessed, possible contamination bias and capacity of the intervention to change attitudes. First, it may be that the CAMI scale was not sensitive enough to show the attitudinal change. The fact is that the CAMI scale was originally developed to assess the general population's attitudes towards community mental health facilities [24], although it has been used with a wide variety of participants, including nurses in psychiatric settings [9] [30]. Moreover, Morris et al. [35] concluded that the validity of the CAMI scale for assessing psychiatric nurses' attitudes is not good. Second, in this study participants and researchers could not be blinded due to the nature of the intervention. Therefore we cannot ensure that no contamination occurred between the study groups. Third, the main aim of the ePsychNurse.Net course was not to change nurses' attitudes to be more positive towards mental illness but to teach nurses to manage distressed and disturbed patients in psychiatric hospitals. Although the ePsychNurse.Net course's modules includes elements related psychiatric nurses' attitudes towards mental illness the strength of the intervention to change nurses' attitudes seems to be too weak. On the other hand, nurses' positive attitudes towards mental illness are in a crucial role when managing distressed and disturbed patients. Thus it is important to explore the ePsychNurse.Net course's impact on nurses' attitudes. It may be that by developing the ePsychNurse.Net course to include more material related to nurses' attitudes towards mental illness the course may be more effective also to change nurses' attitudes.

\section{Conclusion}

Patients with mental illness are stigmatized and nurses may be the perpetuators of stigma. Thus there is a need to ensure that nurses' attitudes related mental illness are positive. One way to influence nurses' attitudes is education. The ePsychNurse.Net course, which was especially developed for nurses' vocational education on managing disturbed and aggressive psychiatric patients, was not found to be effective. However, it may be that by developing the ePsychNurse.Net course to include more material related to nurses' attitudes and as nurses become more familiar with eLearning, the course may be effective in shaping nurses' attitudes towards mental illness.

\section{Acknowledgements}

This study was financially supported by the European Commission (Leonardo da Vinci, FI-06B-F-PP-160701), Hospital District of Helsinki and Uusimaa, and Hyvinkää Hospital Region which are gratefully acknowledged. The authors also wish to acknowledge the contributions of nurses who have taken part in the study.

\section{References}

[1] WHO (2008) Policies and Practices for Mental Health in Europe-Meeting the challenges. World Health Organization, Regional Office for Europe, Copenhagen, Denmark. http://apps.who.int/iris/handle/10665/107366

[2] Department of Health (2009) New Horizons: A Shared Vision for Mental Health. Cross-Governments Strategy: Mental Health Division. London, UK. www.apho.org.uk/resource/item.aspx?RID=83954

[3] WHO (2005) Preparing Health Care Workforce for the $21^{\text {st }}$ Century. The Challenge for Chronic Conditions. World Health Organization, Geneva, Switzerland. http://www.who.int/chp/knowledge/publications/workforce_report.pdf

[4] Schulze, B. (2007) Stigma and Mental Health Professionals: A Review of the Evidence on an Intricate Relationship. International Review of Psychiatry, 19, 137-155. http://dx.doi.org/10.1080/09540260701278929

[5] Thornicroft, G., Brohan, E., Rose, D., Sartorius, N. and Leese, M. (2009) Global Pattern of Experienced and Anticipated Discrimination against People with Schizophrenia: A Cross-Sectional Survey. The Lancet, 373, 408-415. http://dx.doi.org/10.1016/S0140-6736(08)61817-6

[6] Corrigan, P.W. and Larson, J.E. (2008) Stigma. In: Mueser, K.T. and Jeste, D.V., Eds., Clinical Handbook of Schizophrenia, The Guilford Press, New York, 533-540. 
[7] Sartorius, N. (2007) Stigma and Mental Health. The Lancet, 370, 810-811. http://dx.doi.org/10.1016/S0140-6736(07)61245-8

[8] Horsfall, J., Cleary, M. and Hunt, G.E. (2010) Stigma in Mental Health: Clients and Professional. Issues in Mental Health Nursing, 31, 450-455. http://dx.doi.org/10.3109/01612840903537167

[9] Chambers, M., Guise, V., Välimäki, M., Botelho, M.A., Scott, A., Staniuliene, V. and Zanotti, R. (2010) Nurses’ Attitudes to Mental Illness: A Comparison of a Sample of Nurses from Five European Countries. International Journal of Nursing Studies, 47, 350-362. http://dx.doi.org/10.1016/j.ijnurstu.2009.08.008

[10] Ross, C.A. and Goldner, E.M. (2009) Stigma, Negative Attitudes and Discrimination towards Mental Illness within the Nursing Profession: A Review of the Literature. Journal of Psychiatric and Mental Health Nursing, 16, 558-567. http://dx.doi.org/10.1111/j.1365-2850.2009.01399.x

[11] Bak, J., Brandt-Christensen, M., Sestoft, D.M. and Zoffmann, V. (2012) Mechanical Restraint—Which Interventions Prevent Episodes of Mechanical Restraint?-A Systematic Review. Perspectives in Psychiatric Care, 48, 83-94. http://dx.doi.org/10.1111/j.1744-6163.2011.00307.x

[12] Epstein, R. and Hundert, E. (2002) Defining and Assessing Professional Competence. JAMA, 287, $226-235$. http://dx.doi.org/10.1001/jama.287.2.226

[13] Reed, F. and Fitzgerald, L. (2005) The Mixed Attitudes of Nurse’s to Caring for People with Mental Illness in a Rural General Hospital. International Journal of Mental Health Nursing, 14, 249-257. http://dx.doi.org/10.1111/j.1440-0979.2005.00389.x

[14] Välimäki, M., Scott, A., Lahti, M. and Chambers, M. (Eds.) (2008) The Changing Face of Psychiatric Nursing-Care or Control? ePsychNurse.Net. towards Improved Quality-Improving Nurses' Continuing Vocational Training in Psychiatric Hospitals and Inpatient Units. University of Turku, Turku.

[15] Cook, D., Levinson, A. and Garside, S. (2008) Internet-Based Learning in the Health Professions: A Meta-Analysis. JAMA, 30, 1181-1196. http://dx.doi.org/10.1001/jama.300.10.1181

[16] Kontio, R., Lahti, M., Pitkänen, A., Joffe, G., Putkonen, H., Hätönen, H., Katajisto, J. and Välimäki, M. (2011) Impact of eLearning Course on Nurses' Professional Competence in Seclusion and Restraint Practices: A Randomized Controlled Study (ISRCTN32869544). Journal of Psychiatric and Mental Health Nursing, 18, 813-821. http://dx.doi.org/10.1111/j.1365-2850.2011.01729.x

[17] Kontio, R., Hätönen, H., Joffe, G., Pitkänen, A., Lahti, M. and Välimäki, M. (2013) Impact of eLearning Course on Nurses' Professional Competence in Seclusion and Restraint Practices: A 9-Month Follow-Up Results of a Randomized Controlled Study (ISRCTN32869544). Journal of Psychiatric and Mental Health Nursing, 20, 411-418. http://dx.doi.org/10.1111/j.1365-2850.2012.01933.x

[18] Lahti, M., Kontio, R., Pitkänen, A. and Välimäki, M. (2014) Knowledge Transfer from an E-Learning Course to Clinical Practice. Nurse Education Today, 34, 842-847. http://dx.doi.org/10.1016/j.nedt.2013.09.003

[19] Kontio, R., Pitkänen, A., Joffe, G., Katajisto, J. and Välimäki, M. (2014) eLearning Course May Shorten the Duration of Mechanical Restraint among Psychiatric Inpatients: A Cluster-Randomized Trial. Nordic Journal of Psychiatry, 68, 443-449. http://dx.doi.org/10.3109/08039488.2013.855254

[20] Schulz, K., Altman, O. and Moher, D. (2010) CONSORT 2010 Statement: Updated Guidelines for Reporting Parallel Group Randomised Trials. BMJ, 340, c322. http://dx.doi.org/10.1016/j.jclinepi.2010.02.005

[21] Gustafsson, C., Asp, N. and Fagerberg, I. (2007) Reflective Practice in Nursing Care: Embedded Assumptions in Qualitative Studies. International Journal of Nursing Practice, 13, 151-160. http://dx.doi.org/10.1111/j.1440-172X.2007.00620.x

[22] Mann, K., Gordon, J. and MacLeod, A. (2009) Reflection and Reflective Practice in Health Professions Education: A Systematic Review. Advances in Health Sciences Education, 14, 595-621. http://dx.doi.org/10.1007/s10459-007-9090-2

[23] Taylor, S.M., Dear, M.J. and Hall, G.B. (1979) Attitudes toward the Mentally Ill and Reactions to Mental Health Facilities. Social Science and Medicine, 13D, 281-290. http://dx.doi.org/10.1016/0160-8002(79)90051-0

[24] Taylor, S.M. and Dear, M.J. (1981) Scaling Community Attitudes toward the Mentally Ill. Schizophrenia Bulletin, 7, 225-240. http://dx.doi.org/10.1093/schbul/7.2.225

[25] Jones, P.S., Lee, J.W., Phillips, L.R., Zhang, X.E. and Jaceldo, K.B. (2001) An Adaptation of Brislin's Translation Model for Cross-Cultural Research. Nursing Research, 50, 300-304. http://dx.doi.org/10.1097/00006199-200109000-00008

[26] Finkelstein, J., Lapshin, O. and Wasserman, E. (2008) Randomized Study of Different Anti-Stigma Media. Patient Education and Counseling, 71, 204-214. http://dx.doi.org/10.1016/j.pec.2008.01.002

[27] Schafer, T., Wood, S. and Williams, R. (2011) A Survey into Student Nurses’ Attitudes towards Mental Illness: Impli- 
cations for Nurse Training. Nurse Education Today, 31, 328-332. http://dx.doi.org/10.1016/j.nedt.2010.06.010

[28] Wolff, G., Pathare, S., Craig, T. and Leff, J. (1996) Community Attitudes to Mental Illness. British Journal of Psychiatry, 168, 183-190. http://dx.doi.org/10.1192/bjp.168.2.183

[29] Sévigny, R., Wenying, Y., Peiyan, Z., Marleau, J.D., Zhouyun, Y., Lin, S., Guowang, L., Dong, X., Yanling, W. and Haijun, W. (1999) Attitudes towards the Mentally Ill in a Sample of Professionals Working in a Psychiatric Hospital in Beijing (China). International Journal of Social Psychiatry, 45, 41-55. http://dx.doi.org/10.1177/002076409904500106

[30] World Medical Association (2008) World Medical Association Declaration of Helsinki Ethical Principles for Medical Research Involving Human Subjects. http://www.wma.net/en/30publications/10policies/b3/17c.pdf

[31] McCaffrey, R., Hayes, R.M., Cassell, A., Miller-Reyes, S., Donaldson, A. and Ferrell, C. (2012) The Effect of an Educational Programme on Attitudes of Nurses and Medical Residents towards the Benefits of Positive Communication and Collaboration. Journal of Advanced Nursing, 68, 293-301. http://dx.doi.org/10.1111/j.1365-2648.2011.05736.x

[32] Patterson, P., Whittington, R. and Bogg, J. (2007) Testing the Effectiveness of an Educational Intervention Aimed at Changing Attitudes to Self-Harm. Journal of Psychiatric and Mental Health Nursing, 14, 100-105. http://dx.doi.org/10.1111/j.1365-2850.2007.01052.x

[33] Lahti, M., Hätönen, H. and Välimäki, M. (2014) Impact of E-Learning on Nurses’ and Student Knowledge, Skills, and Satisfaction: A Systematic Review and Meta-Analysis. International Journal of Nursing Studies, 51, 136-149. http://dx.doi.org/10.1016/j.ijnurstu.2012.12.017

[34] Kirkpatrick, D.L. (1998) Evaluating Training Programs. The Four Levels. Berrett-Koehler, San Francisco.

[35] Morris, R., Scott, P.A., Cocoman, A., Chambers, M., Guise, V., Välimäki, M. and Clinton, G. (2012) Is the Community Attitudes towards the Mentally Ill Scale Valid for Use in the Investigation of European Nurses’ Attitudes towards the Mentally Ill? A Confirmatory Factor Analytic Approach. Journal of Advanced Nursing, 68, 460-470. http://dx.doi.org/10.1111/j.1365-2648.2011.05739.x

[36] Cobb, S. (2004) Internet Continuing Education for Health Care Professionals: An Integrative Review. The Journal of Continuing Education in the Health Professionals, 24, 171-180. http://dx.doi.org/10.1002/chp.1340240308

[37] Ruiz, J.G., Mintzer, M.J. and Leipzig, R.M. (2006) The Impact of E-Learning in Medical Duration. Academic Medicine, 81, 207-212. http://dx.doi.org/10.1097/00001888-200603000-00002

[38] Bowers, L., Brennan, G., Flood, C., Lipang, M. and Oladapo, P. (2006) Preliminary Outcomes of a Trial to Reduce Conflict and Containment on Acute Psychiatric Wards: City Nurses. Journal of Psychiatric and Mental Health Nursing, 13, 165-172. http://dx.doi.org/10.1111/j.1365-2850.2006.00931.x

[39] Duxbury, J., Hahn, S., Needham, I. and Pulsford, D. (2008) The Management of Aggression and Violence Attitude Scale (MAVAS): A Cross-National Comparative Study. Journal of Advanced Nursing, 62, 596-606. http://dx.doi.org/10.1111/j.1365-2648.2008.04629.x

[40] Henderson, C., Noblett, J., Parke, H., Clement, S., Caffrey, A., Gale-Grant, O., Schulze, B., Druss, B. and Thornicroft, G. (2014) Mental Health-Related Stigma in Health Care and Mental Health-Care Settings. Lancet Psychiatry, 1, 467482. http://dx.doi.org/10.1016/S2215-0366(14)00023-6 